\title{
O Sistema do mérito e as Aptidões Humanas (*)
}

\author{
O. Gienn Stahl \\ Diretor do Bureati of Programs and Stan- \\ dards da United States Civil Service \\ Commission.
}

\section{V}

IVEmos uma era de elevado interêsse nos feitos do homem. Falar dos nossos tempos como "era atômica" ou "era espacial" é não compreender a sua totalidade. São têrmos corriqueiros que superestimam os sucessos da física e ciências correlatas. Ou pior ainda: há nisso algo de alarmante, algo que ameaça a humanidade como se se tratasse do triunfo da matéria sôbre o espírito.

Prefiro pensาr, mais esperançadamente, que estamos no limiar da "era do homcm". Nunca antes estudamos tanto a nós próprios: despertamos para a necessidade de compreensão da motivação humana, e cientistas sociais investigam e tratam da nossa saúde menial e profissional. A ameaça de aniquilamento faz-nos reunir todos os esforços para solucionar as divergências internacionais; a tolerância e a compreensão inter-racial, apesar de tensc̃es e pressões, alcança um nivel nôvo. Não é apenas o bemestar físico e moral que preocupa os governos nacionais e inter nacionais de tôda parte, mas também o desenvolvimento e utilização das aptidões humanas. Transforma-se isso num problema universal; c por tal motivo a educação pública vem adquirindo um significado nôvo ? mais amplo. Exatamente como no Racionalis mo, no Renascimento e na época dos descobrimentos triunfaram o pensamento e o espírito humano, esperamos da mesma maneira poder encarar as aspirações do periodo corrente.

Propondo um reajustamento do nosso senso de valores, um eminente seriador ligou em conexão direta o país e o mundo que nós, americanos, queremos e o modo por que utilizamos os nossos homens. No artigo intitulado "Staffing Freedom", publicado no número de novembro de 1959 de The Atlantic, o senador Joseph S. ClARK, da Pensilvânia, expressa a sua preocupação por não estarmos orientando os mais talentosos jovens para carreiras onde sua inteligência é necessária. Pergunta êle: "como conseguir mais

(*) Traduzido do Civil Service Journal, da United States Civil Service Commission, Vol. I, $\mathrm{n}^{\circ} 4$, abril-junho de 1961. 
e melhores professôres, cientistas, padres, politicos, rabis, ministros, músicos, poetas e sociólogos?" (Poderia ter acrescentado os servidores públicos !) "Para isso conseguir - supõe êle - teremos de reduzir cada vez mais o número de cervejeiros, de donos de boates; e de politiqueiros".

As reflexões do senador, assinalando que "não têm os Estados Unidos nenhum plano ou política nacional de pessoal", levam-no a observar que o plano europeu de educação e ocupação está "muito à frente dos êrros ou acertos do caótico plano americano", e a concluir que o país não precisa de perder a sagrada liberdade "obtendo pela persuação o que já obtiveram outros, pela coação". "Talvez, disse, as pessoas erradas estejam ganhando dinheiro demais e as certas não estejam ganhando o suficiente". Luta êle por "um propósito nacional de liberdade de direção ("staff freedom") com os melhores e mais capazes cérebros, ao invés de deixar as soluções ao acaso".

Não é nôvo tão alto e louvável objetivo. Possivelmente os autores do Civil Service Act, já com 78 anos, teriam tido alguma coisa do mesmo pensamento, ao menos tanto quanto o próprio serviço público era de importância na época. Não obstante todos os seus defeitos e limitações iniciais, o sistema do mérito para o preenchimento de cargos do govêrno estabelecido pela lei em 1883 foi precursor da Era do Homem, pois fundava-se, com efeito, no simples, mas muito nobre propósito de que "os melhores é que haviam de servir ao Estado". Era êste um conceito básico do uso social das aptidões humanas nos Estados Unidos.

Embora anterior à época, a verdadeira idéia de meios organizados de canalização dos maiores talentos para o serviço público de carreira tem poucas ou nenhuma raiz nesta terra de fronteiras internas. Estender-se semelhante e ordenadamente ao planejamento da educação e das aptidões humanas - poderemos dizer que será essa uma das características da Era do Homem? Se assim fôr, que deveremos aprender do conceito de sistema de mérito?

\section{PERSPECTIVA}

Para começar, vejamos em perspectiva o sistema do mérito. Os problemas atualmente enfrentados pelo govêrno federal americano são de atordoantes proporções: a defesa nacional, a competição ideológica e econômica com o comunismo, a conquista do espaço, o aumento da população, mais e melhor educação, a aplicação de um Doutrina de Monroe atualizada, o surgir de novas áreas metropolitanas, os transportes, a conservação da água e de outros recursos, a pesquisa e serviços médicos em número sufi- 
ciente; a harmonia racial, a economia segura, mas dinâmica, o sustento familiar e o desenvolvimento de padrões de vida elevados, são meramente sugestivos do seu raio de ação.

Pode conceber alguém quão mais atordoantes seriam, em verdade quão impossiveis e esmagadores seriam se nestes últimos anos não tivéssemos tido um serviço civil de carreira, fundado no mérito? E' crivel que a politica moderna poderia arcar com problemas tão variados como a conservação da água e as relações internacionais sem a continuidade e a pericia proporcionadas por ım serviço civil competente? Por melhores que possam ser o nosso Legislativo e a liderança política do Executivo, seria racional esperar que a integridade de nossa economia, defesa, ciência, das nossas liberdades mesmo, fôsse preservada pela instalação da mediocridade nos postos de carreira do govêrno? Por mim, penso que não.

Podemos ir mais longe: não é possivel que uma razão importante para o relativo êxito do nosso govêrno comparado com nações mais novas e menos estáveis tenha sido a combinação impar no nosso serviço civil de estabilidade e mérito com receptividade? Imaginar a colocação dêsse serviço civil no mesmo plano que tal explicação, como gente moralmente disciplinada e economia altamente produtiva, não exige esfôrço.

A recente eleição nacional, refletindo como refletiu um interêsse renovado, não lançou dúvidas sôbre a integridade e competência do serviço público civil de carreira. As virtudes, a necessidade mesmo de tal serviço e tal competência, foram testemunhas pelas plataformas dos dois partidos e pelos principais can didatos ao govêrno federal.

\section{FUNDAMENTOS DO SISTEMA DO MÉRITO}

Ei-lo, não necessàriamente com tôdas as suas características atuais e em suas precisas dimensões, mas na essência: é um sistema para assegurar que a competência relativa, e nunca irrelevantes considerações, é que regula a admissão, promoções e prêmios no serviço público, e para assegurar, ainda mais, que está aberta a oportunidade a todos os cidadãos que demonstrarem sua capacidade para êsse serviço.

E' em vista de tais fundamentos que reúno na expressão "sistema do mérito", para os propósitos aqui, não sòmente $\$$ s $86 \%$ da estrutura federal dentro do campo do próprio Civil Servic Act, mas também os verdadeiros sistemas de mérito estabelecidos independentemente, em estatutos ou por ordem administrativa, em numerosas entidades isoladas como o Foreign Service, a Tennesse Valley Anthority e a Atomic Energy Commission. 
Para alguns, o conceito fundamental do sistema do mérito, ou "serviço civil", no seu sentido adjetivo é posse, direitos e proteção dos servidores públicos. Mas atualmente isso é secundário. E note-se que não está diretamente refletido na expressão "sistema do mérito". A proteção de direitos é apenas uma significação, para evitar partidarismos ou outras intromissões prejudiciais à integridade do sistema. A idéia básica é atrair e reter os mais competentes; os direitos de posse ajudam a garanti-lo, reduzindo a possibilidade de represália política. Os direitos de posse, contudo, nunca devem ser usados para manter os incompetentes ou os mediocres no serviço.

O sistema do mérito é, portanto, composto de dois objetivos paralelos:

1) a avaliação do mérito a fim de prover o serviços público de pessoal competente e responsável, e

$2^{\circ}$ ) a garantia de oportunidade aberta à participação dos cidadões nos processos para servir a tal propósito.

\section{A APLiCAÇÃo DaS APTIDÕES huMANAS EM FINS SOCIAIS}

O importante é reconhecer que o sistema do mérito no preenchimento de cargos governamentais foi a primeira idéia em nossa sociedade, fora do alistamento militar, de aplicação em larga escala das aptidões humanas em fins sociais. Implica num desígnio, numa classificação, e coincidentemente numa série de eqüidades que construíram a constituição, expressando o caráter e a capacidade do govêrno americano. Significativa em seus vários efeitos colaterais foi uma conseqüência a que se deu destaque nos primeiros relatórios da Civil Service Commission, por volta de 1880. Era o estimulo à educação pública. Dizia: “. .. o govêrno, empregando em suas repartições os de mais merecimento entre aquêles que o país educou a expensas públicas, honrará e estimulará grandemente o seu sistema de escolas públicas". A História não confirmou a apressada predição.

\section{CRÍTICA VERSUS FATOS}

Nos últimos anos têm alegado os críticos, não sem fundamento, (1) que o nosso sistema de mérito preocupa-se com a metodologia, e (2) que foi êle formulado para um época em que milhares de pessoas solicitavam emprêgo ao govêrno, não para os tempos em que o govêrno precisa de sair e recrutar os especialistas de que necessita.

Tal preocupação maior com a técnica que com as finalidades tem de quando em quando perseguido o sistema federal do mérito, 
e não pode ser contradita. Parte dela, infelizmente, está estabelecida estatutàriamente (não no Civil Service Act, diga-se de passagem) como as cláusulas que exigem a "regra de três", por exemplo, e impedem a classificação dos candidatos em maiores grupos, mais de acôrdo com a capacidade dos testes modernos. Além disso, muito disparate e burocracia, consagrados mais pelo hábito que pelo bom senso, perderam-se desde a segunda guerra mundial. Quando se considera o âmbito de sua cobetura profissional, sua inacreditàvelmente larga descentralização em 800 bancas examinadores em numerosas repartições e localidades, e sua subordinação alternativa ao recrutamento centralizado para assegurar o êxito no atrair milhares de recém-formados cada ano, o sistema federal do mérito em uso, como instrumento empregador, é mais eficiente do que comumente se percebe.

Vários dos processos de uma era menos criadora foram abandonados, porém alguns procedimentos onerosos - razões pelas quais nem sempre agradam ao público - devem permanecer. Têm êles assegurado grandemente aos cidadãos a oportunidade de serem considerados, sem uma exclusão arbitrária, e garantido a inteireza do próprio exame, que no serviço público deve estar acima de críticas, porque, caso não estivesse, estaria frustrada a sua própria finalidade.

Igualmente bem tem-se o sistema do mérito adaptado às exigências do trabalho continuo. Hoje se dá destaque ao recrutamento positivo, como foi, apenas em parte, evidenciado pelo uso de anúncios pagos, visitas regulares aos campos de esporte estudantis, por encarregados especiais de recrutamento em cada zona do serviço civil e nas repartições, o exame em escolas superiores e universidades. Muito dêsse trabalho é tão demorado que se torna ocioso acusar o sistema do mérito de anacrônico a êsse respeito. Há, ainda, por segurança, ênfase nos processos para garantir padrões de qualidade e promover uma classificação para encontrar o mais conveniente, mas não têm sido limitados os esforços para considerar certo pelo recrutamento positivo que a classificação não é exata para os mediocres e os fracamente qualificados.

Sem procurar apresentar neste curto espaço todos os fatos, julgamento e perspectiva que seriam necessários para compreender o planejamento da utilização das aptidões humanas para tôda a nossa sociedade a fim de ir de encontro ao incisivo desafio do Senador Clark, ou avizinhar-me dos dificeis objetivos propostos por outros sensiveis observadores, posso oferecer sòmente algumas idéias de como a nossa experiência com o sistema do mérito pode relacionar-se com tais aspirações. 


\section{BALANÇO}

Cêrca de oito décadas de experiência com o sistema federal do mérito comprovaram, de um modo geral, numerosos pontos, uns previstos, outros não. Muitos dêles prendem-se à totalidade das fontes sociais de planejamento e desenvolvimento das capacidades humanas. Eu poderia identificar assim os pontos mais importantẹ:

12) O sistema do mérito tem sido a causa maior da continuidade e geral qualidade do serviço civil da União.

2.) O sistema estabeleceu meios de classificação dos candidatos relativamente válidos e altamente aceitáveis, compativeis por inteiro com as nossas tradições de democracia e igualdade.

3.) O sistema de provas tem mostrado ser uma aproximação prática de um verdadeiro sistema de mérito, isto é, de competência no serviço público; e até hoje não foi inventado nenhum outro processo aproximativo tão bom .

4) O sistema de provas há muito goza da confiança do Congresso, do Executivo, de numerosos grupos de estudos imparciais, de organizações de empregados e veteranos, e do público em geral.

$\left.5^{\circ}\right)$ Os processos utilizados nos testes do govêrno têm merecido fé, sendo copiados e tomados de empréstimo por empregadores do govêrno ou não, de todo o país.

6:) O sistema de concurso demonstrou o quanto é prático o exame objetivo, com ou sem provas escritas, e de padrões de qualidade baseados na análise da ocupação combinada com os variáveis mercados de trabalho.

$7^{\circ}$ ) O sistema não só estimulou a educação pública, como também tem-se adaptado e correspondido ao produto das instituições educacionais americanas de vários níveis, além de refletir cada dia mais intimas relações de cooperação com milhares de escolas secundárias, escolas profissionais e universidades.

8:) O sistema tem fornecido uma formidável reafirmação contra a discriminação politica, religiosa ou racial no serviço público.

9:) O serviço público federal, com o sistema do mérito. vem servindo de laboratório gigantesco para o estudo e experimentação de modernas técnicas de seleção e de outras técnicas de pessoal.

Isto não significa que se tenha conseguido tudo. São ainda necessários uns poucos melhoramentos vitais, estando alguns já em execução. Muitos de nós temos necessidade de muito mais pesquisa que as que os modestos recursos correntes tornam pos- 
síveis, a fim de avançar dramàticamente nos métodos de seleção de pessoal e correlatos. O planejamento da utilização das aptidões humanas e as substituições dentro do serviço estão ainda na infância. Uma especial atenção é exigida no equipamento da administração do pessoal para as posições de direção, incluindo problemas de seleção, promoção, avaliação e incentivos.

$E^{\prime}$ um desafio verdadeiramente grande. Para que a América continue a crescer, a transforma-se, a avançar. As qualidades de adaptação e flexibilidade que tão efetivamente sustentaram o sistema do mérito no passado deverão ser no futuro continuamente aproveitadas.

\section{RELAÇÕES MAIS VASTAS}

Mas vejamos agora as maiores conseqüências.

Se temos necessidade de mais planejamento, mais ordem, mais estimulo em relação aos extraordinários objetivos sociais na educação de nossa juventude e na direção, desenvolvimento e utilização do potencial humano nesta Era do Homem, podem algumas lições ser talvez tiradas, então, da longa e vitoriosa experiência com o sistema do mérito no serviço civil nos Estados Unidos. Prova ao menos que os padrões que qualidade para o serviço público são coerentes com a liberdade, que as distinções entre os individuos resultantes dos exames são compativeis com a democacia, que a competência gera o prestígio e vice-versa, que as barreiras aos preconceitos ou mesmo "aos laços de velha amizade" auxiliam a manter a integridade da maquinaria governamental.

Mas afirmativamente, contudo, permanece o sistema do mérito como notável exemplo do engenho americano - com todo o aprêço devido aos antepassados britânicos - em prover de pessoal e manter um apreciável espírito representativo, de alta qualidade, e um serviço público federal verdadeiramente adequado. Reconhecendo o autogevêrno como o maior dos objetivos sociais, podemos concluir, com razão, que o sistema do mérito é uma contribuição significativa à aurora da Era do Homem. E podemos estar certos de que tudo quanto deve ser feito para ajustar a nossa visão das aptidões humanas aos problemas da época, o próprio serviço civil de carreira, em vista do sistema do mérito, há de fazer em grande parte. 